\title{
Significance and Survival of Enterococci During the House Fly Development
}

Author(s): Anuradha Ghosh , Mastura Akhtar Chris Holderman , and Ludek Zurek Source: Journal of Medical Entomology, 51(1):63-67. 2014.

Published By: Entomological Society of America

URL: http://www.bioone.org/doi/full/10.1603/ME13161

BioOne (www.bioone.org) is a nonprofit, online aggregation of core research in the biological, ecological, and environmental sciences. BioOne provides a sustainable online platform for over 170 journals and books published by nonprofit societies, associations, museums, institutions, and presses.

Your use of this PDF, the BioOne Web site, and all posted and associated content indicates your acceptance of BioOne's Terms of Use, available at www.bioone.org/page/terms of use.

Usage of BioOne content is strictly limited to personal, educational, and non-commercial use. Commercial inquiries or rights and permissions requests should be directed to the individual publisher as copyright holder. 


\title{
Significance and Survival of Enterococci During the House Fly Development
}

\author{
ANURADHA GHOSH, ${ }^{1}$ MASTURA AKHTAR, ${ }^{2,3}$ CHRIS HOLDERMAN, ${ }^{2,4}$ AND LUDEK ZUREK ${ }^{1,2,5}$
}

\begin{abstract}
J. Med. Entomol. 51(1): 63-67 (2014); DOI: http://dx.doi.org/10.1603/ME13161
ABSTRACT House flies are among the most important nonbiting insect pests of medical and veterinary importance. Larvae develop in decaying organic substrates and their survival strictly depends on an active microbial community. House flies have been implicated in the ecology and transmission of enterococci, including multi-antibiotic-resistant and virulent strains of Enterococcus faecalis. In this study, eight American Type Culture Collection type strains of enterococci including Enterococcus avium, Enterococcus casseliflavus, Enterococcus durans, Enterococcus hirae, Enterococcus mundtii, Enterococcus gallinarum, Enterococcus faecalis, and Enterococcus faecium were evaluated for their significance in the development of house flies from eggs to adults in bacterial feeding assays. Furthermore, the bacterial colonization of the gut of teneral flies as well as the importance of several virulence traits of E. faecalis in larval mortality was assessed. Overall survival of house flies (egg to adult) was significantly higher when grown with typically nonpathogenic enterococcal species such as E. hirae (76.0\% survival), E. durans (64.0\%), and E. avium (64.0\%) compared with that with clinically important species E. faecalis (24.0\%) and E. faecium (36.0\%). However, no significant differences in survival of house fly larvae were detected when grown with E. faecalis strains carrying various virulence traits, including isogenic mutants of the human clinical isolate E. faecalis V583 with in-frame deletions of gelatinase, serine protease, and capsular polysaccharide serotype C. Enterococci were commonly detected in fly puparia (range: $75-100 \%$; concentration: $10^{3}-10^{5} \mathrm{CFU} /$ puparium); however, the prevalence of enterococci in teneral flies varied greatly: from 25.0 (E. casseliflavus) to $89.5 \%$ (E. hirae). In conclusion, depending on the species, enterococci variably support house fly larval development and colonize the gut of teneral adults. The human pathogenic species, E. faecalis and $E$. faecium, poorly support larval development and are likely acquired in nature by adult flies during feeding. House fly larvae do not appear to be a suitable model organism for assessment of enterococcal virulence traits.
\end{abstract}

KEY WORDS house fly, Enterococcus spp., larval development, gut colonization

Animal manure, household waste, and other decaying organic substrates provide a suitable habitat for the development of muscoid flies, including house flies (Diptera: Muscidae) (Keiding 1986). House fly larvae strictly depend on the active microbial community in the habitat to develop and complete their life cycle (Schmidtmann and Martin 1992, Watson et al. 1993, Zurek et al. 2000). The principle of this symbiosis is unknown; it is possible that larvae require bacteria as a source of essential nutrients and/or bacteria contribute to digestion and absorption of nutrients (Espinosa-Fuentes and Terra 1987). It has also been

${ }^{1}$ Department of Diagnostic Medicine and Pathobiology, Kansas State University, 221K Mosier Hall, Manhattan, KS 66506.

${ }^{2}$ Department of Entomology, Kansas State University, 123 Waters Hall, Manhattan, KS 66506.

${ }^{3}$ Present address: Department of Food Science and Nutrition, University of Minnesota, 225 Food Science and Nutrition, 1334 Eckles Ave., St. Paul, MN 55108.

${ }^{4}$ Present address: Department of Entomology, University of Florida, P.O. Box 110620, Steinmetz Hall, 1881 Natural Area Drive, Gainesville, FL 32611

${ }^{5}$ Corresponding author, e-mail: lzurek@ksu.edu. shown that larval survival varies greatly depending on the bacterial species (Zurek et al. 2000).

House flies have been implicated as a mechanical or bioenhanced vector of a number of human and animal pathogens, including enterococci (reviewed in Graczyk et al. 2001, Zurek and Gorham 2008). Enterococci are ubiquitous, gram-positive cocci that comprise the intestinal microbiota of healthy animals (Jackson et al. 2009, Kojima et al. 2010), including that of house flies $\left(10^{2}-10^{4} \mathrm{CFU}\right.$ per house fly) (Macovei and Zurek 2006). However, some strains of Enterococcus faecalis and Enterococcus faecium are of great human clinical importance and cause serious nosocomial infections such as bacteremia, endocarditis, and urinary tract infections (de Perio et al. 2006). Enterococcus casseliflavus, Enterococcus gallinarum, E. faecalis, E. faecium, and Enterococcus hirae were isolated from insects in several studies previously (Macovei and Zurek 2006, Graham et al. 2009, Channaiah et al. 2010, Ahmad et al. 2011). However, the significance of enterococci in the house fly larval development and their colonization of the gut of teneral adults are unknown. 
Table 1. Description of strains and mutants of E. faecalis used in this study

\begin{tabular}{|c|c|c|}
\hline Strain & Description & References \\
\hline V583 & $\begin{array}{l}\text { Clinical strain (ATCC 700802), serotype C, vancomycin-resistant, gelatinase-, and } \\
\text { serine protease-positive }\end{array}$ & Sahm et al. 1989 \\
\hline 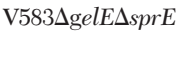 & $\begin{array}{l}\text { Isogenic deletion mutant of V583, gelatinase-, and serine protease-defective, } \\
\text { tetracycline- and spectinomycin-resistant }\end{array}$ & Hancock and Perego 2004 \\
\hline $\mathrm{V} 583 \Delta c p s C$ & Isogenic deletion mutant of V583, capsule serotype C-deficient & Thurlow et al. 2009 \\
\hline MMH594 & Epidemic clinical strain, serotype $\mathrm{C}$, hemolytic, high-level gentamicin-resistant & Huycke et al. 1991 \\
\hline OG1X & $\begin{array}{l}\text { Clinical strain, streptomycin-resistant, aggregation substance-, cytolysin-, and } \\
\text { gelatinase-defective }\end{array}$ & Ike et al. 1983 \\
\hline OG1RF & $\begin{array}{l}\text { A derivative of clinical strain OG1, serotype B laboratory strain (ATCC } \\
47077 \text { ), rifampicin- and fusidic acid-resistant, gelatinase-positive }\end{array}$ & Dunny et al. 1978 \\
\hline JH2-2 & $\begin{array}{l}\text { A derivative of clinical strain } \mathrm{JH} 2 \text {, plasmid-free, aggregation substance-, } \\
\text { cytolysin-, and gelatinase-defective }\end{array}$ & Yagi and Clewell 1980 \\
\hline FA2-2(pAM714) & $\begin{array}{l}\text { Laboratory strain, serotype C, cytolysin-positive, gelatinase-, and serine protease- } \\
\text { defective }\end{array}$ & Ike and Clewell 1984 \\
\hline
\end{tabular}

Furthermore, some insects (e.g., Manduca sexta and Galleria mellanella) have been used as animal models for studying bacterial virulence factors (Gaspar et al. 2009, Mason et al. 2011). Due to rapid development, nonexpensive rearing, absence of adaptive immunity, and the gut microbial community that commonly comprises enterococci, house flies could be a suitable model system for assessing enterococcal virulence traits.

Our study aimed to: 1) assess the significance of different enterococcal species in the development of house fly larvae, 2) determine the transstadial survival of enterococci from larva to adult, and 3) test whether house fly larvae can serve as a model to assess virulence traits of enterococci.

\section{Materials and Methods}

Enterococcal Strains. Eight enterococcal species type strains (from American Type Culture Collection, ATCC) were used in our experiments: Enterococcus avium ATCC 14025, E. casseliflavus ATCC 25788, Enterococcus durans ATCC 19432, E. hirae ATCC 8043, Enterococcus mundtii ATCC 43186, E. gallinarum ATCC 49573, E. faecalis ATCC 19433, and E. faecium ATCC 19434. In addition, eight E. faecalis strains and isogenic deletion mutants of E. faecalis V583 were tested (Table 1).

Egg Yolk Tryptic Soy Agar (EYTSA). Tryptic soy agar (Difco, BD Diagnostic Systems, Sparks, MD) with egg yolk was prepared as described by Watson et al. (1993) and Zurek et al. (2000).

Surface Sterilization of House Fly Eggs. Eggs were harvested from the laboratory house fly colony (maintained at $25 \pm 2{ }^{\circ} \mathrm{C}, 70 \pm 10 \% \mathrm{RH}$, and a photoperiod of 18:6 [L:D] h) and immediately surface sterilized following the protocol described previously (Zurek et al. 2000). Surface-sterilized eggs were transferred aseptically on sterile moist black filter paper in sterile petri dishes, and incubated at $28^{\circ} \mathrm{C}$ until hatching.

Bioassays. EYTSA was inoculated with fresh cultures of the individual bacterial strains and incubated overnight at $37^{\circ} \mathrm{C}$. The first-instar larvae were transferred aseptically with a sterile brush to EYTSA. Each bioassay was conducted with five larvae per plate per enterococcal strain in five replicates. We used 10 lar- vae per plate per strain in three replicates for the bioassays performed with E. faecalis strains. Un-inoculated EYTSA with first-instar larvae was used as negative control. All plates were incubated at $28^{\circ} \mathrm{C}$ and examined daily for larval mortality and pupation. The pupae were weighed, surface sterilized, and transferred on sterile filter paper in sterile petri dishes for incubation at $28^{\circ} \mathrm{C}$ until adult emergence. Pupation, weight of pupae, adult emergence, and survival rates (egg to adult) were recorded.

Determination of Enterococcal Concentration in Teneral Adults and Puparia After Adult Emergence. Each emerged adult fly was immediately surface sterilized as described earlier for eggs. Surface-sterilized adults and empty puparia were homogenized in $1.0 \mathrm{ml}$ phosphate buffered saline ( $\mathrm{pH} 7.2$; MP Biomedicals, Solon, $\mathrm{OH}$ ) and dilution plated on m-Enterococcus agar (BBL, BD Diagnostic Systems, Sparks, MD). Enterococcal colonies were confirmed phenotypically and by the esculin hydrolysis test as described previously (Macovei and Zurek 2007). Concentration of enterococci was calculated as $\mathrm{CFU} /$ puparium or $\mathrm{CFU} / \mathrm{fly}$.

Statistical Analysis. Data on pupation, fly emergence, fly survival (egg to adult), and enumeration of enterococci in adults and puparia were checked for normal distribution by Shapiro-Francia test (Royston 1993), then transformed with arcsine square root (arcsine sqrt [percent/100]) to stabilize error variance (Gomez and Gomez 1984), and analyzed using analysis of variance. Means were compared by the leastsquares means protocol $(P=0.05)$ of the general linear model (SAS Institute 2003). Although all tests of significance (with exception of pupal weight) were based on the transformed data, the untransformed percent values are reported. Percent pupation and survival of flies reared on various strains and mutants of E. faecalis were analyzed using analysis of variance $(P<0.05)$ and the post hoc Tukey test.

\section{Results}

Significance of Enterococci in Larval Development and Gut Colonization of Teneral Adults. Bioassays using EYTSA confirmed that house fly larvae fail to 
Table 2. Significance and survival of enterococci in the gastrointestinal tract during the house fly development $($ egg to adult) $(n=$ 25 per enterococcal species)

\begin{tabular}{|c|c|c|c|c|c|c|c|c|}
\hline \multirow{2}{*}{$\begin{array}{l}\text { Enterococcal } \\
\text { species }\end{array}$} & \multirow{2}{*}{$\begin{array}{l}\text { Pupation } \\
\quad(\%)\end{array}$} & \multirow{2}{*}{$\begin{array}{l}\text { Pupa wt }(g) \\
\text { mean } \pm \mathrm{SD}\end{array}$} & \multirow{2}{*}{$\begin{array}{c}\text { Adult } \\
\text { emergence } \\
(\%)\end{array}$} & \multirow{2}{*}{$\begin{array}{c}\text { Survival (egg } \\
\text { to adult) } \\
(\%)\end{array}$} & \multirow{2}{*}{$\begin{array}{c}\text { Teneral adults } \\
\text { with enterococci } \\
(\%)\end{array}$} & \multirow{2}{*}{$\begin{array}{c}\text { Puparia with } \\
\text { enterococci } \\
(\%)\end{array}$} & \multicolumn{2}{|c|}{$\begin{array}{c}\text { Enterococci }(\mathrm{CFU} / \mathrm{ml}) \\
\text { mean } \pm \mathrm{SD}\end{array}$} \\
\hline & & & & & & & Adult & Puparium \\
\hline E. avium & $68.0^{\mathrm{abc}}$ & $0.019 \pm 0.003^{\mathrm{ab}}$ & $94.1^{\mathrm{a}}$ & $64.0^{\mathrm{a}}$ & $37.5^{\mathrm{c}}$ & $88.0^{\mathrm{b}}$ & $5.9 \pm 8.2$ by $10^{2}$ & $1.2 \pm 2.6$ by $10^{5}$ \\
\hline E. casseliflavus & $68.0^{\mathrm{abc}}$ & $0.021 \pm 0.002^{\mathrm{a}}$ & $70.6^{\mathrm{bc}}$ & $48.0^{\mathrm{b}}$ & $25.0^{\mathrm{c}}$ & $85.7^{\mathrm{cd}}$ & $7.7 \pm 9.4$ by $10^{2}$ & $1.4 \pm 1.6$ by $10^{3}$ \\
\hline E. durans & $76.0^{\mathrm{ab}}$ & $0.018 \pm 0.008^{\mathrm{b}}$ & $84.2^{\mathrm{ab}}$ & $64.0^{\mathrm{a}}$ & $87.5^{\mathrm{b}}$ & $88.9^{\mathrm{b}}$ & $0.7 \pm 2.6$ by $10^{5}$ & $2.7 \pm 3$ by $10^{3}$ \\
\hline E. hirae & $80.0^{\mathrm{a}}$ & $0.020 \pm 0.004^{\mathrm{ab}}$ & $95.0^{\mathrm{a}}$ & $76.0^{\mathrm{a}}$ & $89.5^{\mathrm{a}}$ & $100^{\mathrm{a}}$ & $0.6 \pm 2.4$ by $10^{5}$ & $1.8 \pm 3.6$ by $10^{5}$ \\
\hline E. mundtii & $52.0^{\mathrm{cd}}$ & $0.019 \pm 0.003^{\mathrm{ab}}$ & $92.3^{\mathrm{ab}}$ & $52.0^{\mathrm{b}}$ & $30.8^{\mathrm{c}}$ & $100^{\mathrm{bc}}$ & $3.0 \pm 3.2$ by $10^{2}$ & $5.3 \pm 5.7$ by $10^{3}$ \\
\hline E. gallinarum & $72.0^{\mathrm{ab}}$ & $0.019 \pm 0.036^{\mathrm{ab}}$ & $50.0^{\mathrm{d}}$ & $36.0^{\mathrm{bc}}$ & $33.3^{c}$ & $100^{\text {cde }}$ & $6.6 \pm 5.7$ by $10^{5}$ & $4.7 \pm 2.6$ by $10^{3}$ \\
\hline E. faecalis & $48.0^{\mathrm{d}}$ & $0.020 \pm 0.002^{\mathrm{ab}}$ & $50.0^{\mathrm{cd}}$ & $24.0^{\mathrm{c}}$ & $50.0^{\mathrm{c}}$ & $100^{\mathrm{de}}$ & $0.6 \pm 1.0$ by $10^{4}$ & $1.1 \pm 0.08$ by $10^{3}$ \\
\hline E. faecium & $60.0^{\text {bcd }}$ & $0.019 \pm 0.002^{\mathrm{ab}}$ & $60.0^{\mathrm{cd}}$ & $36.0^{\mathrm{bc}}$ & $33.3^{\mathrm{c}}$ & $75.0^{\mathrm{e}}$ & $1.1 \pm 1.3$ by $10^{2}$ & $1.6 \pm 3.7$ by $10^{5}$ \\
\hline
\end{tabular}

Values within the same column followed by the same letter are not significantly different $(P>0.05)$.

develop beyond the first instar in sterile media and bacterial strains were required to complete larval development. Overall, the highest proportion $(80.0 \%)$ of larvae reached the pupa stage when grown with $E$. hirae and this was statistically significant compared with larvae reared on $E$. mundtii $(P=0.0014), E$. faecalis $(P=0.0004)$, and $E$. faecium $(P=0.0176)$ (Table 2). A significantly lower proportion of fly pupation was observed with the potentially human pathogenic species E. faecalis (48.0\%) compared with that of all other strains, except E. faecium $(P=0.1461)$ and $E$. mundtii $(P=0.6266)$ (Table 2$)$.

The mean pupal weight ranged from 0.018 to 0.020 $\mathrm{g}$ and did not differ significantly among E. avium, $E$. gallinarum, E. durans, E. hirae, E. mundtii, E. faecalis, and E. faecium (Table 2). Only fly larvae grown with E. casseliflavus had a significantly greater pupal weight compared with those fed on $E$. durans $(P=0.0117)$ (Table 2).

Regardless of the strain, adult flies started to emerge in 4-5 d after pupation. The proportion (\%) of adult emergence was significantly higher with $E$. hirae (95.0\%, $P=0.0003,0.0013,0.0002)$, E. avium (94.1\%, $P=0.0003,0.0013,0.0002)$, E. mundtii $(92.3 \%, P=$ $0.0007,0.0026,0.0003)$, and $E$. durans $(84.2 \%, P=$ $0.0052,0.0173,0.0025)$ compared with that with $E$. faecalis $(50.0 \%)$, E. faecium $(60.0 \%)$, and E. gallinarum $(50.0 \%)$. The adult emergence on E. hirae did not differ significantly from that with E. avium $(94.1 \%, P=$ $1.0)$, E. mundtii $(92.3 \%, P=0.8)$, and E. durans $(84.2 \%$, $P=0.3228)$ (Table 2$)$.

The overall survival rate of house fly larvae (egg to adult) was highest from EYTSA with E. hirae (76.0\%), followed by E. avium (64.0\%) and E. durans (64.0\%). A significantly lower survival to the adult stage was recorded with $E$. faecalis $(24.0 \%)$ compared with that on E. hirae $(P<0.0001)$, E. avium $(P<0.0001)$, E. mundtii $(P=0.0013)$, E. durans $(P<0.0001)$, and $E$. casseliflavus $(P=0.0013)$ (Table 2$)$.

Transstadial Survival of Enterococci From Larva to Adult. Prevalence of enterococci in the gut of teneral adults ranged from 25.0 to $89.5 \%$ (Table 2 ). The most frequent gut colonization was recorded from flies with E. hirae (89.5\%) followed by E. durans (87.5\%) and that was significantly higher $(P<0.0001$ and $P<0.01$, respectively) comparing with that of all other entero- coccal species. The lowest colonization rate was observed from flies with E. casseliflavus (25.0\%). The overall enterococcal concentration ranged from $10^{2}$ to $10^{5} \mathrm{CFU} / \mathrm{fly}$ and varied widely among individual flies. Enterococcus gallinarum survived in the fly gut throughout the development with the highest concentration of $6.6 \pm 5.7 \times 10^{5} \mathrm{CFU} /$ fly (Table 2 ).

Empty puparia were also examined for the presence of enterococci. The majority of puparia (75-100\%) were positive for enterococci. All puparia were positive for E. hirae, E. faecalis, E. gallinarum, and E. mundtii on EYTSA (Table 2). Across different enterococcal species, the mean bacterial concentration per puparium ranged from $10^{3}$ to $10^{5} \mathrm{CFU}$ (Table 2).

Significance of E. faecalis With Different Virulence Traits in Larval Mortality. Various clinical strains of $E$. faecalis supported larval development (pupation range: $36-52 \%$; range of survival from egg to adult stage: $14-28 \%$ ) to similar extent as recorded for $E$. faecalis ATCC 19433 (Fig. 1). Group-wise analysis showed that there was no significant difference among different strains and virulence mutants tested in terms of fly pupation $(P=0.953)$ and survival to the adult stage $(P=0.806)$ (Fig. 1$)$.

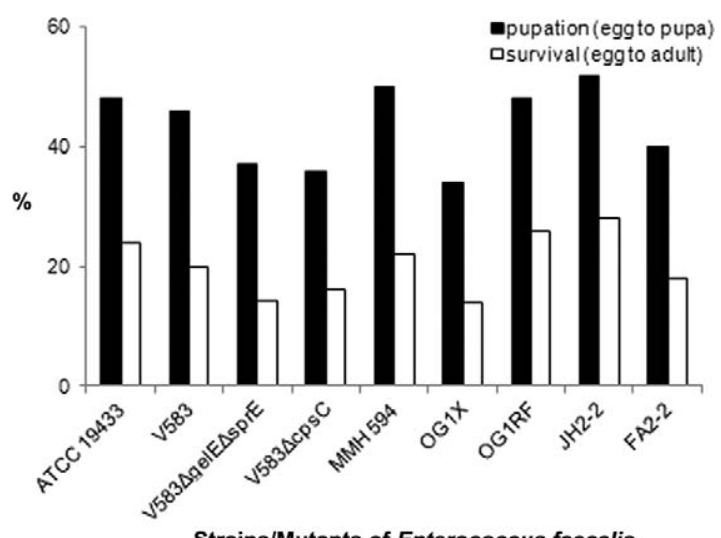

Fig. 1. Pupation and survival of house flies on different strains of Enterococcus faecalis ( $n=30$ per strain). 


\section{Discussion}

House flies have been implicated as mechanical or bioenhanced vectors for several human pathogenic bacteria such as Salmonella spp., Campylobacter spp., Pseudomonas aeruginosa, Listeria spp., Vibrio spp., and Escherichia coli O157:H7 (reviewed by Graczyk et al. 2001, Zurek and Gorham 2008). Previous studies have shown that house flies also commonly carry antibioticresistant and potentially virulent enterococci (Macovei and Zurek 2006, Graham et al. 2009, Ahmad et al. 2011). Furthermore, the house fly digestive tract provides a suitable habitat for enterococcal growth (Doud and Zurek 2012) and horizontal transfer of antibiotic resistance genes (Akhtar et al. 2009). Previously, we have also demonstrated that house flies have a great potential to contaminate human food with enterococci in a short period (Macovei et al. 2008, Doud and Zurek 2012). Consequently, this insect may represent a link between the agricultural and urban environment for antibiotic resistance traits. However, the significance of enterococci in house fly larval development and the gut colonization of teneral adult flies by enterococci were unknown.

Our bioassays confirmed the data from previous studies (Schmidtmann and Martin 1992, Zurek et al. 2000) showing that live bacteria are required for the successful house fly development to the adult stage. The overall fly survival rate from eggs to adults varied greatly depending on the enterococcal species and this likely reflects differences in metabolic properties (e.g., utilization and fermentation of carbohydrates, hydrolysis of amino acids) among individual enterococcal species (Farrow and Collins 1985, De Vaux et al. 1998, Vancanneyt et al. 2001). The highest percentage of house fly pupation and survival to the adult stage was observed with E. hirae and this species also commonly colonized the gut of teneral adults. This indicates that E. hirae is well adapted to the house fly gut environment and fly developmental processes from larvae to adults. Enterococcus hirae is also the most common enterococcal species detected in manure of pigs (Ahmad et al. 2011), pastured cattle and bison (Anderson et al. 2008), and feedlot cattle (L. Z., unpublished). In contrast, E. hirae was not detected in wild house fly adults, including those from fast foodrestaurants (Macovei and Zurek 2006) and poultry farms (Graham et al. 2009), and it was found only in very low prevalence in house flies from swine farms (Ahmad et al. 2011), feedlot and pastured cattle (L. Z., unpublished), and waste water treatment plants (Doud et al. 2014). It is possible that the gut microbiome of adult house flies changes over time depending on their food sources and E. hirae in adult house flies is digested and replaced by other enterococcal species, primarily by E. faecalis. This is corroborated indirectly by the fact that although E. faecalis supported the larval development of house flies to the least extent, it was the most commonly detected enterococcal species in the digestive tract of adult house flies collected from various environments (Macovei and Zurek 2006, Graham et al. 2009, Ahmad et al. 2011,
Doud et al. 2014). In addition, our recent study (Doud and Zurek 2012) reported the colonization and proliferation of E. faecalis in the crop and midgut of adult house flies, demonstrating that this insect is a bioenhanced vector for $E$. faecalis. Future studies focusing on the analysis of the bacterial community in the digestive tract of wild teneral adults are needed to better understand the transstadial bacterial survival and how this affects the vector capacity of flies for animal and zoonotic pathogens.

We were also interested in assessing house fly larvae as a novel model organism for testing putative virulence traits including gelatinase, serine protease, aggregation substance, capsular polysaccharide, and cytolysin that are associated with pathogenic strains of E. faecalis (Gilmore 2002). Although, on the species level, E. faecalis supported house fly development poorly ( $24.0 \%$ survival), there was no significant difference in the fly development among E. faecalis strains with or without putative virulence factors. This includes the clinical strain E. faecalis V583 and its isogenic mutants without gelatinase, serine protease, and capsular polysaccharide serotype $\mathrm{C}$. Therefore, based on our bacterial feeding assays, larvae of Musca domestica were not found to be suitable as a model organism for testing enterococcal infection and virulence.

In conclusion, enterococci, depending on the species, support house fly larval development and colonize the gut of teneral adults to various degrees. The human pathogenic species, E. faecalis and E. faecium, do not support larval development to great extent and are likely acquired in nature by adult flies during feeding and eventually outcompete other enterococcal species in the fly digestive tract. House fly larvae do not appear to be a suitable model organism for assessment of enterococcal virulence traits.

\section{Acknowledgments}

We thank Aqeel Ahmad for his help in the statistical analysis. This study was funded by the Multi-State project S1030. This is contribution no. 14-128-J from the Kansas Agricultural Experiment Station.

\section{References Cited}

Ahmad, A., A. Ghosh, C. Schal, and L. Zurek. 2011. Insects in confined swine operations carry a large antibiotic resistant and potentially virulent enterococcal community. BMC Microbiol. 11: 23.

Akhtar, M., H. Hirt, and L. Zurek. 2009. Horizontal transfer of the tetracycline resistance gene tet $M$ mediated by pCF10 among Enterococcus faecalis in the house fly (Musca domestica L.) alimentary canal. Microb. Ecol. 58: 509-518.

Anderson, J. F., T. D. Parrish, M. Akhtar, L. Zurek, and H. Hirt. 2008. Antibiotic resistance of enterococci in American bison (Bison bison) from a nature preserve compared to that of enterococci in pastured cattle. Appl. Environ. Microbiol. 74: 1726-1730.

Channaiah, L. H., B. Subramanyam, L. J. McKinney, and L. Zurek. 2010. Stored-product insects carry antibiotic-resistant and potentially virulent enterococci. FEMS Microbiol. Ecol. 74: 464-471. 
de Perio, M. A., P. R. Yarnold, J. Warren, and G. A. Noskin. 2006. Risk factors and outcomes associated with nonEnterococcus faecalis, non-Enterococcus faecium enterococcal bacteremia. Infect. Control Hosp. Epidemiol. 27: $28-33$.

De Vaux, A., G. Laguerre, C. Diviès, and H. Prévost. 1998. Enterococcus asini, sp. nov. isolated from the caecum of donkeys (Equus asinus). Int. J. Syst. Bacteriol. 48: 383-387.

Doud, C. W., and L. Zurek. 2012. Enterococcus faecalis OG1RF:pMV158 survives and proliferates in the house fly digestive tract. J. Med. Entomol. 49: 150-155.

Doud, C. W., H. M. Scott, and L. Zurek. 2014. Role of house flies in the ecology of Enterococcus faecalis from wastewater treatment facilities. Microb. Ecol. (in press).

Dunny, G. M., B. L. Brown, and D. B. Clewell. 1978. Induced cell aggregation and mating in Streptococcus faecalis: evidence for a bacterial sex pheromone. Proc. Natl. Acad. Sci. USA 75: 3479-3483.

Espinosa-Fuentes, F. P., and W. R. Terra. 1987. Physiological adaptations for digesting bacteria. Water fluxes and distribution of digestive enzymes in Musca domestica larval midgut. Insect. Biochem. 17: 809-817.

Farrow, J.A.E., and M. D. Collins. 1985. Enterococcus hirae, a new species that includes amino acid assay strain NCDO 1258 and strains causing growth depression in young chickens. Int. J. Syst. Bacteriol. 35: 73-75.

Gaspar, F., N. Teixeira, L. Rigottier-Gois, P. Marujo, C. Nielsen-LeRoux, M. T. Crespo, M. F. Lopes, and P. Serror. 2009. Virulence of Enterococcus faecalis dairy strains in an insect model: the role of $f_{s r} B$ and gelE. Microbiology 155: $3564-3571$.

Gilmore, M. S. 2002. The enterococci: pathogenesis, molecular biology, and antibiotic resistance. ASM Press, Washington, DC.

Gomez, K. A., and A. A. Gomez. 1984. Statistical procedures for agricultural research, 2nd ed. Wiley, New York.

Graczyk, T. K., R. Knight, R. H. Gilman, and M. R. Cranfield. 2001. The role of non-biting flies in the epidemiology of human infectious diseases. Microbes Infect. 3: 231-235.

Graham, J. P., L. B. Price, S. L. Evans, T. K. Graczyk, and E. K. Silbergeld. 2009. Antibiotic resistant enterococci and staphylococci isolated from flies collected near confined poultry feeding operations. Sci. Total Environ. 407: 27012710.

Hancock, L. E., and M. Perego. 2004. The Enterococcus faecalis $f_{s r}$ two-component system controls biofilm development through production of gelatinase. J. Bacteriol. 186: $5629-5639$

Huycke, M. M., C. A. Spiegel, and M. S. Gilmore. 1991. Bacteremia caused by hemolytic, high-level gentamicinresistant Enterococcus faecalis. Antimicrob. Agents Chemother. 35: 1626-1634.

Ike, Y., and D. B. Clewell. 1984. Genetic analysis of the pAD1 pheromone response in Streptococcus faecalis, using transposon $\operatorname{Tn} 917$ as an insertional mutagen. J. Bacteriol. 158: 777-783.

Ike, Y., R. A. Craig, B. A. White, Y. Yagi, and D. B. Clewell. 1983. Modification of Streptococcus faecalis sex pheromones after acquisition of plasmid DNA. Proc. Natl. Acad. Sci. U.S.A. 80: 5369-5373.

Jackson, C. R., P. J. Fedorka-Cray, J. A. Davis, J. B. Barrett, and J. G. Frye. 2009. Prevalence, species distribution and antimicrobial resistance of enterococci isolated from dogs and cats in the United States. J. Appl. Microbiol. 107: $1269-1278$.

Keiding, J. 1986. The house fly: biology and control. WHO Vector Control Series 63.

Kojima, A., A. Morioka, M. Kijima, K. Ishihara, T. Asai, T. Fujisawa, Y. Tamura, and T. Takahashi. 2010. Classification and antimicrobial susceptibilities of Enterococcus species isolated from apparently healthy food-producing animals in Japan. Zoonoses Public Health. 57: 137-141.

Macovei, L., and L. Zurek. 2006. Ecology of antibiotic resistance genes: characterization of enterococci from houseflies collected in food settings. Appl. Environ. Microbiol. 72: 4028-4035.

Macovei, L., and L. Zurek. 2007. Influx of enterococci and associated antibiotic resistance and virulence genes from ready-to-eat food to the human digestive tract. Appl. Environ. Microbiol. 73: 6740-6747.

Macovei, L., B. Miles, and L. Zurek. 2008. The potential of house flies to contaminate ready-to-eat food with antibiotic resistant enterococci. J. Food Protect. 71: 432- 439

Mason, K. L., T. A. Stepien, J. E. Blum, J. F. Holt, N. H. Labbe, J. S. Rush, K. F. Raffa, and J. Handelsman. 2011. From commensal to pathogen: translocation of Enterococcus faecalis from the midgut to the hemocoel of Manduca sexta. mBio 2: 3 e00065-11.

Royston, P. 1993. A pocket-calculator algorithm for the Shapiro-Francia test for non-normality: an application to medicine. Stat. Med. 12: 181-184.

Sahm, D. F., J. Kissinger, M. S. Gilmore, P. R. Murray, R. Mulder, J. Solliday, and B. Clarke. 1989. In vitro susceptibility studies of vancomycin-resistant Enterococcus faecalis. Antimicrob. Agents Chemother. 33: 1588-1591.

SAS Institute. 2003. SAS online 9.1. SAS Institute, Cary, NC.

Schmidtmann, E. T., and P.A.W. Martin. 1992. Relationship between selected bacteria and the growth of immature house flies, Musca domestica, in an axenic test system. J. Med. Entomol. 29: 232-235.

Thurlow, L. R., V. C. Thomas, and L. E. Hancock. 2009. Capsular polysaccharide production in Enterococcus faecalis and contribution of $\mathrm{CpsF}$ to capsule serospecificity. J. Bacteriol. 191: 6203-6210.

Vancanneyt, M., C. Snauwaert, I. Cleenwerck, M. Baele, P. Descheemaeker, H. Goossens, B. Pot, P. Vandamme, J. Swings, F. Haesebrouck, et al. 2001. Enterococcus villorum sp. nov., an enteroadherent bacterium associated with diarrhea in piglets. Int. J. Syst. Evol. Microbiol. 51: 393-400.

Watson, D. W., P.A.W. Martin, and E. T. Schmidtmann. 1993. Egg yolk and bacteria growth medium for Musca domestica (Diptera: Muscidae). J. Med. Entomol. 30: 820-823.

Yagi, Y., and D. B. Clewell. 1980. Recombination-deficient mutant of Streptococcus faecalis. J. Bacteriol. 143: 966-970.

Zurek, L., and J. R. Gorham. 2008. Insects as vectors of foodborne pathogens, pp. 1-16. In J. G. Voeller (ed.), Wiley handbook of science and technology for homeland security. Wiley Inc., Hoboken, NJ.

Zurek, L., C. Schal, and D. W. Watson. 2000. Diversity and contribution of the intestinal bacterial community to the development of Musca domestica (Diptera: Muscidae) larvae. J. Med. Entomol. 37: 924-928.

Received 13 August 2013; accepted 5 November 2013. 